\title{
Obstetric ultrasound: Indications and referral in a diagnostic imaging facility in Makurdi, North-central Nigeria
}

\author{
Utoo $\mathrm{BT}^{1 *}$ and Hameed $\mathrm{M}^{2}$ \\ ${ }^{1}$ Department of Obstetrics and Gynaecology, Benue State University Teaching Hospital, Makurdi, Nigeria \\ ${ }^{2}$ Department of Radiology, Benue State University Teaching Hospital, Makurdi, Nigeria
}

\begin{abstract}
Background: Ultrasonography is an indispensable tool in Obstetric and Gynecological practice. Usually, trained health personnel are expected to request for a scan based on a valid indication as well as providing relevant clinical information to the sonographer.

Objective: To determine the indications and source of referral for Obstetric ultrasound scan at a diagnostic imaging facility.

Methods: A retrospective data extraction from the health records at a Diagnostic Imaging Centre in Makurdi by a trained health record staff, between May and July 2016. SPSS version 20 was used to analyze data. Chi square was used as a test of statistics with P-value $\leq 0.05$ at $95 \% \mathrm{CI}$ as significant.

Results: Five hundred (500) patients were studied; most (58.4\%) were aged 20-29 years. Majority (97.6\%) were married. Most (46.8\%) had tertiary education, were multiparous (67.4\%), civil servants (36.6\%) and Christians (76.6\%). While 297 (59.4\%) of patients were referred by health workers for ultrasound scan, 203 (40.6\%) were self-referrals. As much as $261(52.2 \%)$ of the patients did not have stated indication, out of which $113(43.3 \%), 64(24.5 \%), 52(19.9 \%), 32(12.3 \%)$ were referred by self, Community health workers, Nurse/Midwife and doctors respectively. The stated indications included; Fetal wellbeing $21 \%$, viability $6 \%$, diagnosis of pregnancy $4.8 \%$, dating $3.2 \%$, gender determination $2.6 \%$, placenta localization $2.2 \%$, vaginal bleeding $2.2 \%$ amongst others. Source of referral was significantly related to level of education and indications $(\mathrm{P} \leq 0.05)$.
\end{abstract}

Conclusion: Self-referral and non-stated indications for Obstetric scan especially amongst the self-referrals and lower cadre of health personnel was significantly high. Stated indications include; fetal wellbeing, viability, diagnosis and dating of pregnancy. Education and enlightenment of patients and training of Health personnel on Obstetric ultrasound is recommended.

\section{Introduction}

Ultrasonography is an indispensable tool in Obstetric and Gynecological practice worldwide [1-3]. It is usually referred to as the third eye of the Obstetrician. Actually, ultrasound brought about a remarkable revolution in clinical practice since the 1950s when it was popularized by Ian Donald at Glasgow. Today; there are few Obstetric conditions that do not require a contribution from ultrasonography for management. Several women feel their pregnancies are not complete without at least one ultrasound scan [3]. However, several years back and up till now, the routine use of ultrasound scan has been considered to be controversial $[4,5]$.

Despite the debate whether the clinician request or not, pregnant women would opt to do a scan for several reasons which may not be considered necessary to the clinician at that moment [4]. A study done in Enugu, South East Nigeria showed half of the women interviewed expressing the view that women should have the right to request for a scan at any time [5]. This argument of source of referral notwithstanding, the technology of ultrasonography offers the clinician the opportunity of assessing the fetal status, dynamics and morphology with high resolution images sometimes with $3 \mathrm{D}$ or $4 \mathrm{D}$ scanners.

The information received by the clinician from the sonographic computations and assessment done by a competent sonographer with adequate knowledge of fetal anatomy, physiology and biochemistry can enable fetal intrauterine therapy. So, the technology of fetal ultrasonography has moved from just mere diagnostic purposes to therapeutic adventures in maternal-fetal medicine. Some of the diagnostic uses of ultrasonography in obstetrics include; Diagnosis of pregnancy, gestational age estimation, vaginal bleeding of unknown origin, suspected multiple gestation, adjunct to amniocentesis, suspected hydatidiform mole, adjunct to cervical cerclage placement, suspected intra uterine fetal demise (IUFD) and sex determination etc.

The challenge in modern ultrasonography is where self-referrals are made, useful clinical information are missing which may affect the accuracy of the procedure as well as interpretation of results thereby creating the possibility of patient mis-management. Similarly, referrals by lower cadre of health personnel with a lot of inadequacies create

*Correspondence to: Utoo B.T (MB; BCh; FWACS; FMCOG), Senior Lecturer/ Consultant Obstetrician \& Gynecologist, Benue State University Teaching Hospital, Makurdi, Nigeria, Tel: +2348033725168; E-mail: bernardutoo@yahoo.com, btutoo86@gmail.com

Key words: ultrasound, obstetrics, pregnancy, indications, referral, Fetal wellbeing

Received: November 23, 2018; Accepted: December 05, 2018; Published: December 10, 2018 
problems for the managing physician. The sonographer on the other hand particularly in a private diagnostic facility, do not bother about the source of referral whether it was by a physician, other cadre of health personnel or self because of the economic gains derived from the procedure. Generally, there is a poor awareness and knowledge on when to do an ultrasound scan, who should request for it and the expertise of the procedure in our environment. More so, the pattern of source of referral and what the indications are have not been published in our environment of clinical practice hence the need to have a baseline data for further research work.

\section{Objectives}

To determine the source of referral and indications for Obstetric ultrasound scan at a private diagnostic imaging facility.

\section{Methodology/Study design}

A retrospective study in which data of clients who had Obstetric scan at the Musafaha Diagnostic Imaging Centre in Makurdi between May and July 2016 was extracted from the electronic records by a trained record staff of the facility. The facility is a private facility that receives referrals from all tiers of health care delivery centers in the state. All the scans were done using a Toshiba ultrasound machine (4D nemio Toshiba Medical system Corporation, Otawara-Japan) fitted with endovaginal and curvilinear transducers with frequencies of $6 \mathrm{MHz}$ and $3.7 \mathrm{MHz}$ respectively. First trimester pregnancies were evaluated with the endovaginal transducer while others were done using curvilinear. All the scans were done by a single person which is the consultant radiologist.SPSS version 20 (IBM), New York, USA was used to analyze data. Chi square was used as a test of statistics with Pvalue $\leq 0.05$ at $95 \% \mathrm{CI}$ as significant.

\section{Results}

Five hundred (500) patients were studied; most (58.4\%) were aged 20-29 years. Majority (97.6\%) were married. Most (46.8\%) had tertiary education, were multiparous $(67.4 \%)$, civil servants $(36.6 \%)$ and Christians (76.6\%). While 297 (59.4\%) of patients were referred by health personnel for ultrasound scan, 203 (40.6\%) were self-referrals. As much as $261(52.2 \%)$ of the patients did not have stated indication on referral forms, out of which 113 (43.3\%), 64(24.5\%), 52(19.9\%), $32(12.3 \%)$ were referred by self, Community health workers, Nurse/ Midwife and doctors respectively. The stated indications include; Fetal wellbeing $21 \%$, viability $6 \%$, diagnosis of pregnancy $4.8 \%$, dating $3.2 \%$, gender determination $2.6 \%$, placenta localization $2.2 \%$, vaginal bleeding 2.2\% amongst others. Women who were educated are more likely to get a referral from a clinician $(\mathrm{P} \leq 0.05)$.

\section{Discussion}

Most of the women as seen in Table 1 were in the age bracket of 20 - 29 and followed by 30-39 years. This constitute the reproductive ages at which most women get married and hope to complete their reproductive careers respectively. This finding is similar to that of Eze et al. About $60 \%$ of the referrals for Obstetric scans were done by health personnel. This is similar to the findings of the study in Sokoto where most scans were requested by clinicians. However, in a similar study in Enugu all scans were requested by clinicians $[1,5]$. It is actually ideal for the clinician to initiate prenatal ultrasound scan not just as a routine procedure but with a valid indication so as to make the test more relevant to patient care.

The finding of lower cadre of health personnel being involved in requesting for USS is as a result of the fact that the centre is a private
Table 1. Socio-demographic features of the women

\begin{tabular}{|c|c|c|}
\hline Age Group & Frequency(N 500) & Percentage $(100 \%)$ \\
\hline$\leq 19$ & 33 & 6.6 \\
\hline $20-29$ & 292 & 58.4 \\
\hline $30-39$ & 169 & 33.8 \\
\hline $40-49$ & 6 & 1.2 \\
\hline \multicolumn{3}{|l|}{ Marital Status } \\
\hline Single & 52 & 10.4 \\
\hline Married & 448 & 89.6 \\
\hline \multicolumn{3}{|l|}{ Education } \\
\hline None & 19 & 3.8 \\
\hline Primary & 54 & 10.8 \\
\hline Secondary & 193 & 38.6 \\
\hline Tertiary & 234 & 46.8 \\
\hline \multicolumn{3}{|l|}{ Parity } \\
\hline 0 & 127 & 25.4 \\
\hline $1-4$ & 337 & 67.4 \\
\hline$\geq 5$ & 36 & 7.2 \\
\hline \multicolumn{3}{|l|}{ Occupation } \\
\hline Trading & 161 & 32.2 \\
\hline Civil Servant & 183 & 36.6 \\
\hline Farmer & 25 & 5.0 \\
\hline Students & 49 & 9.8 \\
\hline Housewife & 82 & 16.4 \\
\hline \multicolumn{3}{|l|}{ Tribe } \\
\hline Tiv & 197 & 39.4 \\
\hline Idoma & 84 & 16.8 \\
\hline Igede & 20 & 4.0 \\
\hline Hausa & 100 & 20.0 \\
\hline Igbo & 48 & 9.6 \\
\hline Yoruba & 8 & 1.6 \\
\hline Others & 43 & 8.6 \\
\hline \multicolumn{3}{|l|}{ Religion } \\
\hline Christians & 373 & 74.6 \\
\hline Muslims & 127 & 25.4 \\
\hline
\end{tabular}

imaging centre. Patients are more at home were such request could be accommodated. The worry however is whether these cadres of personnel do have the required clinical skill to guarantee a sensible request, interpretation of results and patient care or appropriate referral. The fact that most of the non-stated indication were from these lower cadre of health personnel compared with that of the doctor as seen in the study suggests their clinical competence is doubtful (Figure 1).

Similarly, of significant interest is generally the large number of self-referrals (40\%). Some of the clients could be attending or intended to attend ante natal care in private, secondary or primary health care centers. At times women want to satisfy their curiosity or have an experience. On the other hand, most women feel they have the right to scan at any time, and a legitimate reason to do so [5]. They will seek for a scan if it is not requested for because they expect that it should be done [3].

Although it is good to do intrauterine assessment of fetal wellbeing especially in early pregnancy to detect the presence of fetal problems that may require prompt treatment, some clinicians are compelled by their clients to being addicted to USS. These clients have the assumption that ultrasound machine can detect all problems or diseases in the human body. In fact, outside of Obstetric practice this procedure has replaced clinical skill of most clinicians today. These clinicians scan before taking history and doing physical examination! This happens mostly with private practitioners and medical officers in secondary public health institutions. This is a bad attitude for young clinicians who at times 
work in such environments because their clinical skill becomes blunted as they later seek to grow in their professional career. Thus, the act of clinical clerksmanship is unfortunately lost.

This study like other similar studies have shown as demonstrated in Table 2 that education of the women significantly influences the use of Obstetrics ultrasound scan $[1,5,6]$. The more educated a woman is the more likely she is to get a referral from a physician to do an Obstetric scan. This clearly demonstrates the importance of a girl child education. There is also need for public health enlightenment at preferably antenatal care clinics for ultrasound scan focusing on availability, recommended period, referral system and dispelling myths and misconception about the procedure. The finding of as much as $148(56.7 \%)$ of referrals without stated indications amongst health workers including clinicians clearly demonstrates the need to inform and train the health personnel about ultrasonography [7]. A clearly stated indication will help the sonographer to be more focus during the procedure so as to come out with a more useful report for the managing clinician. Secondly, the myth of over estimating the diagnostic power of the ultrasound machine will be aborted.
The commonest indications as seen in Table 3 were fetal wellbeing, fetal viability, pregnancy diagnosis, dating, gender determination, vaginal bleeding e.t.c.This is similar to findings in other studies $[2,4,8,9]$. Especially the young women married or unmarried who are not on contraceptives, at times conception happen without a prior plan hence the need to confirm with USS. Again, the possibility of a diagnostic dilemma or lack of access or confidence in other methods of testing for pregnancy in which case USS is required to settle the matter [10]. For those who have a desirable pregnancy it is normal for the woman to want to have assurance of normal fetal development. Again, it is possible that some women especially the primigravidae, those who were on contraceptives, breastfeeding mothers etc not to remember the ages or dates of their pregnancies hence the need for dating with an early USS.

Gender determination is most at times premised on preference for a particular sex [2,11]. In our settings in Africa, most families prefer the male sex due to issues of inheritance and continuity of family lineage. It is therefore not a strange request by women even in their

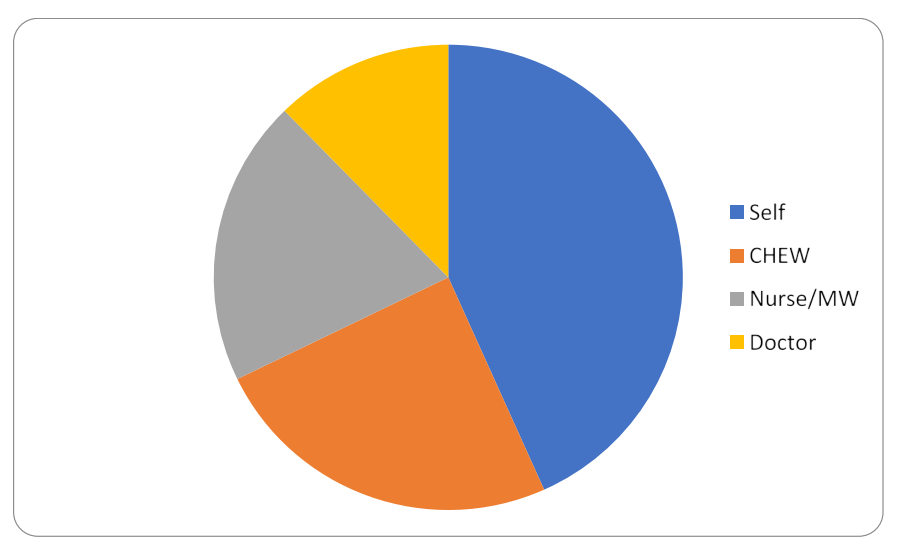

Figure 1. Sources of referral among non-stated indications

Table 2. Relationship between education and source of referral

\begin{tabular}{|c|c|c|c|c|c|}
\hline & & & \multicolumn{2}{|c|}{ Scan Requested by who } & \multirow{2}{*}{ Total } \\
\hline & & & Self & Doctor & \\
\hline \multirow{8}{*}{ Level of Education } & \multirow{2}{*}{ None } & Count & 6 & 13 & 19 \\
\hline & & $\%$ within Level of Education & $31.6 \%$ & $68.4 \%$ & $100.0 \%$ \\
\hline & \multirow{2}{*}{ Primary } & Count & 24 & 30 & 54 \\
\hline & & $\%$ within Level of Education & $44.4 \%$ & $55.6 \%$ & $100.0 \%$ \\
\hline & \multirow{2}{*}{ Secondary } & Count & 65 & 128 & 193 \\
\hline & & $\%$ within Level of Education & $33.7 \%$ & $66.3 \%$ & $100.0 \%$ \\
\hline & \multirow{2}{*}{ Tertiary } & Count & 108 & 126 & 234 \\
\hline & & $\%$ within Level of Education & $46.2 \%$ & $53.8 \%$ & $100.0 \%$ \\
\hline \multirow{2}{*}{\multicolumn{2}{|c|}{ Total }} & Count & 203 & 297 & 500 \\
\hline & & \% within Level of Education & $40.6 \%$ & $59.4 \%$ & $100.0 \%$ \\
\hline
\end{tabular}

Pearson Chi Square $=7.799, \mathrm{df}=3$, sig 2-tail $=0.05, \mathrm{p}=0.047$

Table 3. Indications for ultrasonography

\begin{tabular}{|c|c|c|}
\hline Indication & Frequency(N=500) & Percentage (100\%) \\
\hline Not stated & 261 & 52.2 \\
\hline Fetal wellbeing & 105 & 21.0 \\
\hline Fetal viability & 30 & 6.0 \\
\hline Diagnosis of pregnancy & 24 \\
\hline Dating & 16 & \\
\hline Gender determination & 13 & 3.8 \\
\hline Vaginal bleeding & 11 & 2.6 \\
\hline Others & 40 & 2.2 \\
\hline
\end{tabular}


first conferment's to prefer a baby boy so as to cement their position in their newly contracted marriages. Ekele et al reported that women who had a prior female baby are more likely to scan for fetal gender than those who had a prior male baby [11]. In some communities such as in India, sex selective scans are even used for the purpose of selective abortions [10]. Suboptimal care during the antenatal period in resource constrained environments like ours also make USS for biophysical profiling necessary in pregnancies complicated with hypertension, diabetes mellitus, sickle cell disease, cardiac disorders, asthma etc.

Interestingly, Nigerian women on a general note as reflected in this study have demonstrated a high level of awareness, belief and acceptability in ultrasound unlike in other environments where there are cultural, social and psychological barriers to acceptability and utilization of ultrasound services where they exist $[10,12]$.

\section{Conclusion/Recommendation}

Self-referral and non-stated indications for Obstetric scan especially amongst the self-referrals and lower cadre of health personnel was significantly high. Stated indications include; fetal wellbeing, viability, diagnosis and dating of pregnancy. Education and enlightenment of women and training of Health personnel on Obstetric USS is recommended.

\section{Limitations of the study}

1. Gaps in information on data for certain clients typical of a retrospective study.

2. The high number of non-stated indications over-tasked the sonographer and will subsequently affect the result made available to the managing physician for the care of the client.

\section{Acknowledgement}

We thank Miss Ngunan for entering the Data into the computer and Mr. Victor for analyzing the data.

\section{Conflict of interest}

The authors have no conflict of interest to declare.

\section{References}

1. Oche MO, Umar AS, Raji MO, Kaoje AU, Godwin G, et al. (2013) Knowledge of the Use and Indications for Obstetric Ultrasound Scan among Women Attending a Main Referral Hospital, Sokoto, Nigeria. Research in Obstet Gynaecol 2:55-62.

2. Edvardsson K, Graner S, Thi LP, Åhman A, Small R, et al. (2015) 'Women think pregnancy management means obstetric ultrasound': Vietnamese obstetricians' views on the use of ultrasound during pregnancy. Glob Health Action 8: 28405. [Crossref]

3. Filly RA, Crane JP (2002) Routine obstetric sonography. J Ultrasound Med 21: 713 718. [Crossref]

4. Enakpene CA, Morhason-Bello IO, Marinho AO, Adedokun BO, Kalejaiye AO, et al (2009) Client's reasons for prenatal ultrasonography in Ibadan, south west of Nigeria. BMC women's Health 9:12.

5. Ikeako L, Ezegwui H, Onwudiwe E, Enwereji J (2014) Attitude of expectant mothers on the use of ultrasound in pregnancy in a tertiary institution in South East of Nigeria. Ann Med Health Sci Res 4: 949-953. [Crossref]

6. Gonzaga MA, Kiguli-Malwadde E, Francis B, Rosemary B (2009) Current Knowledge, attitudes and practices of expectant women towards routine sonography in pregnancy at Naguru health center, Uganda. Pan Afr Med J 3:18.

7. LaGrone LN, Sadasivam V, Kushner AL, Groen RS (2012) A review of training opportunities for ultrasonography in low- and middle-income countries. Trop Med Int Health 17: 808-819. [Crossref]

8. Ranji A, Dykes AK (2012) Ultrasound screening during pregnancy in Iran: Women's expectations, experiences and number of Scan. Midwifery 28: 24-29.

9. Roberts J, Griffiths FE, Verran A, Ayre C (2015) Why do women seek ultrasound scan from commercial providers during pregnancy? Sociol Health Illn 37: 594-609. [Crossref]

10. Firth ER, Mlay P, Walker R, Sill PR (2011) Pregnant women's beliefs, expectations and experiences of antenatal ultrasound in Northern Tanzania. Afr J Reprod Health 15: 91-107. [Crossref]

11. Ekelle BA, Maaji SM, Bello SO, Marhason-Bello IO (2008) Profile of women seeking fetal gender at ultrasound in a Nigerian Obstetric population. Ultrasound 16: 199-202.

12. Ugwu AC, Udoh BE, Eze JC, Eze PC (2011) Awareness of information, expectations and experiences among women for obstetric sonography in a south east Nigerian population. East Afr J Public health 8: 132-134.

Copyright: (C2018 Utoo BT. This is an open-access article distributed under the terms of the Creative Commons Attribution License, which permits unrestricted use, distribution, and reproduction in any medium, provided the original author and source are credited. 